\title{
Introduction: Special Issue on Feminism and Family Life
}

\author{
Maxine Baca Zinn ${ }^{1} \&$ Heather E. Dillaway ${ }^{2}$
}

\begin{abstract}
This thematic issue presents a feminist examination of family life. In their introduction, the guest editors describe the papers in this special issue and position the work of family sociologists in the context of feminist thought. Four themes are included: Inequality and Diversity, False Dichotomies, Men in Families, and Distinctive Standpoints. Taken together, the articles and the books reviewed in this issue expand our current knowledge about some of the most pressing issues facing the family field today.
\end{abstract}

Key Words: Family life, feminism, gender equity, marriage, caregiving, diversity, false dichotomies, men in families, distinctive standpoints

${ }^{1}$ Maxine Baca Zinn, Ph.D., is Professor, Department of Sociology, Michigan State University, 316 Berkey Hall, East Lansing, MI, 48824. Electronic mail may be sent via the Internet to zinnm@msu.edu

${ }^{2}$ Heather E. Dillaway, Ph.D., is Assistant Professor, Department of Sociology, Wayne State University, 2228 Faculty Administration Building, Detroit, MI, 48202. Electronic mail may be sent via the Internet to dillaway@wayne.edu

Feminism has revolutionized the family field. Probably no field of study is more profoundly influenced by feminist thought. In the four decades since feminist scholars introduced a gendered understanding of family life, the field has absorbed feminist influences. Feminist concepts and investigative strategies have produced new descriptions of family experience, conceptualized family forms and family processes in new ways, and identified new topics for investigation. Feminist scholars have also illustrated the general importance of family studies, elevating our general interest in and concern for this social institution; studies of families and family life are now seen as parallel to studies of individuals or groups in other social institutions.

Michigan Family Review, 10, 1-6, 2005 C Michigan Council on Family Relations 
Unlike other disciplines, which marginalize feminist works, the family field now incorporates key feminist elements into its very core. Not all family scholars work from an explicitly feminist perspective, but many feminist concerns have become embedded in the foundational frameworks of the field. At the same time, feminist research and activism flourish throughout the family domain. Family researchers and practitioners can draw from a voluminous and generative feminist literature on every conceivable family topic.

This issue of the Michigan Family Review undertakes a feminist examination of family life. A call for papers produced a submission of 10 papers, which were then reviewed by referees. We anticipated that papers submitted and finally selected would present a blend of theoretical, empirical, and practice-based orientations, and that they would strike a balance between family related disciplines. This was not the case. In both submissions and final selections, sociological studies outnumber the others. Although all contributors are sociologists, the articles use intellectual traditions drawn from a variety of disciplines along with wide-ranging methods of inquiry.

To make our feminist issue of the Michigan Family Review as current and comprehensive as possible, we invited scholars to review recently published books on gender and family and to pay special attention to their feminist and policy implications. The books selected for review include the topics of gender equity in national family and work policy (Jacobs and Gerson), caregiving among families of different class locations (Hansen), the impact of Viagra on intimate relationships (Loe), men's contemporary experiences of fatherhood (Townsend), the uniqueness of African American families (Hill), and a history of marriage (Coontz). While the books represent the national community of feminist family scholars, many of the research-based articles in this issue examine family life in Michigan communities. All of the contributors to this collection have strong connections to Michigan colleges and universities.

We have tried to make this issue appealing to family scholars and practitioners as well as feminists across a range of disciplines. The selection of each article was guided by its scholarly merit and by questions such as these: Is it informed by feminist principles? Does it reflect current feminist thought? Does it open the family field to new kinds of gender questions?

\section{Feminist Themes}

The collection is, in many respects, exemplary of the present character of feminist research on families. The contents are not easily categorized: If there is a unifying thread, it will be found in the persistent attention given to different contexts 
and social locations that produce a range of family experiences for women and men. All of the articles move family analysis beyond dichotomous simplifications of women's and men's experiences as well. Although gender in families remains an anchor point, it is always contingent on other dimensions of difference such as social class, race, and sexual orientation. The following themes reflected in the articles also are central to current feminist thought on the family.

\section{Inequality and Diversity}

Broad systems of inequality produce differentiated family outcomes. While all articles in this special issue touch on the importance of individuals' and families' social locations, this theme is made especially clear by Barbara Wells of Maryville College, as she describes how families (in particular, mothers) in rural Michigan communities negotiate work and family responsibilities within the context of class and place. As economic restructuring occurs and rural areas lose jobs, working class families face instability and must reorganize their strategies for earning money and taking care of their families. Middle-class families in the same rural communities, however, continue to engage in similar paid work and family activity. Therefore Wells illustrates that the effects of economic restructuring within certain geographic communities differ depending on families' class locations.

In her study of the autobiographies of South African and African American women activists, Monica White of Wayne State University also explicates how the gender locations of women in families and women's membership within raciallydefined families can initiate their move towards activism and activist identities. More specifically, Black women activists in White's study discuss how they modeled their resistance upon other family members' racially-motivated resistance, how experiences within families often generated their resistance (especially when those experiences highlighted gender and racial oppression), the creation of familylike ties through activism around racial issues, and their redefinition of conventional, gendered family forms once involved in activism. White's study is important because it details how race, gender, and family locations intersect to create individuals' resistance to systems of inequality over time.

Nancy Mezey of Monmouth University describes in detail the methodological choices she made while completing a focus group study of lesbian mothers and childfree lesbians and, in this way, also documents the importance of inequality and diversity. The purpose of Mezey's research was to find out how race, class, gender, and sexuality shaped the motherhood choices of lesbians in Michigan communities. Yet, in the end, she found that these locations affected more than just motherhood choices; they impacted her experience of recruitment and sampling as well. She concludes that her own White, middle-class location - that is, her lack of 
connection to many of the women she recruited - mattered more at times than a common sexuality location. In addition, some women by virtue of their race and class locations were able to make more of a choice for or against motherhood. Mezey reminds readers to think about how difference and inequality can impact the basic options individuals have in creating families.

The book reviews by Byrnes, Fitzgerald, and Laube also make the theme of inequality and diversity explicit. Specifically, Byrnes outlines Hansen's focus on the commonalities and differences in caregiving strategies across diverse class locations. Fitzgerald details Coontz' attention to the importance of race, class, gender and sexuality variations in the institution of marriage over time and place. Laube illustrates Hill's argument that we need to pay more attention than we have to the race variations in family experience and, specifically, the uniqueness of African American family experience over time.

\section{False Dichotomies}

Feminist scholars have long critiqued the arbitrary and faulty divisions between family and paid work. Two articles in this special issue expose the close connections between work and family. They contribute to the well-established feminist critique of the public/private, productive/reproductive division by showing how work, families, and communities are part of a single gendered system. Elizabeth Paré and Heather Dillaway of Wayne State University use their conceptual piece to dissect contemporary conceptualizations of "stay-at-home" versus "working" mothers. These authors illustrate the contradictions within each term, the overlaps across the two terms, and contrast our conceptualizations of these terms with evidence of the lived experiences of parents and workers. They document, for instance, how "stay-at-home" mothers are often working for pay (both in and out of the home) and how "working" mothers often define themselves by their mothering behavior first. They also describe how some women mother for income, contradicting the very division of the two terms. In addition, Paré and Dillaway explain how current economic conditions prohibit any strict division of parenting and paid work. The authors conclude that feminist family scholars must work on reconceptualizations of parenthood and paid work, so that the terminology (e.g., working vs. staying at time) we utilize to discuss family and work mirrors lived experience.

Elizabeth Ann Whitaker of Michigan State University also highlights the complicated connections between work and family lives in exploring middle- and upper-class women's experiences of having to move geographically for spouses' jobs. Specifically looking at the decision to move, Whitaker highlights how women in her pilot study face an undue gendered burden of acquiescing to a move (and then 
moving) when their husbands are relocated. While women lose connections to community and often sacrifice their own options for paid work, their male counterparts typically gain opportunities in paid work as a result of geographical moves. Yet, because relocation for paid work is seen as a sign of success and because considerable importance is placed on men's paid work (in comparison to women's), wives felt they could not question the wisdom of the move. Overall Whitaker's work suggests that the contours of women's lives are often determined by the conditions of their husbands' paid work. Thus she highlights how work and family are intimately connected in gendered ways.

Wells makes it clear that women's decisions about family life are often dependent upon their and their husbands' income strategies as well. And Kelly's review of Jacobs and Gerson's book illustrates that gendered divisions between family and work have made their way into national policy. Thus, feminist family scholars also need to engage in policy reformation to eradicate false dichotomies.

\section{Men in Families}

A critical examination of men and masculinity in family settings is a vital part of recent feminist family inquiry. While no article in this special issue is wholly dedicated to the experiences of men, Paré and Dillaway highlight how men's lives are as affected as women's by changing economic structures and the interconnections of parenting and paid work. Indeed, while there is no public debate about "stay-at-home" versus "working" fathers (like there is about mothers), fathers are making similar decisions to mothers about how to combine and negotiate parenting and paid work. Hernandez' review of Nicholas Townsend's book and Kingry's review of Meika Loe's book also highlight the importance of studying men's participation within caregiving and intimate relationships. Paré and Dillaway, Hernandez, and Kingry all clarify the important place that men hold within families, and how men's lived experiences often diverge from ideologically defined roles or positions. All authors' mention of men in families suggests that considerably more feminist exploration of men's locations within families, especially in relation to women, is necessary to fully understand family and gender experiences.

\section{Distinctive Standpoints}

The experiences, outlooks, and voices of diverse groups of women and men produce new ways of seeing and understanding family life. Thus the authors of feminist family studies often apply (and reformulate) qualitative methodologies to call on voices not often represented. The articles and book reviews in this special issue follow this tradition. Mezey's article is based on eight focus groups completed with women identifying as lesbians. Whitaker and Wells gathered their data from 
individual interviews (eight and thirteen respectively) with women who faced different work-family situations. Book reviews by Kingry, Byrnes, and Hernandez also show that much of the new feminist family scholarship is based on individual interviews with people who are currently negotiating complex family decisions and processes. White engaged in a qualitative textual analysis of six autobiographies, specifically using a grounded theory approach to decipher themes arising out of these texts. Even though Paré and Dillaway do not report on their own empirical research, much of the literature they pull on to critique conceptualizations of parenting and paid work is based on qualitative research; they also call for more qualitative research so that we can understand better the unique ways in which individuals combine and negotiate family and work. The book review by Laube illustrates Hill's similar call for future research.

We thank all those who submitted papers for this issue, the anonymous reviewers, and Libby Blume for coordinating the many editorial tasks required to produce this collection. The articles and books reviewed capture well the transformational capacities of feminist family inquiry. Taken together, the articles and the books reviewed in this issue expand our current knowledge about some of the most pressing issues facing the family field today. They illustrate how we as feminist scholars and practitioners can push the academic study of family, gender, and social policy further than we already have. 